\title{
Perianal Abscess; Simple Drainage versus Drainage and Fistulotomy
}

\author{
Aly Saber ${ }^{1}$, Emad K. Bayumi \\ ${ }^{1}$ Department of General Surgery, Port-Fouad General Hospital, Port-Fouad, Egypt \\ ${ }^{2}$ General Surgery, Medical Academy Named After S. I. Georgiesky of Crimea Federal University, Crimea, Russia
}

Email address:

Alysaber54@gmail.com (A. Saber), Emadsurg666@hotmail.com (E. K. Bayumi)

\section{To cite this article:}

Aly Saber, Emad K. Bayumi. Perianal Abscess; Simple Drainage versus Drainage and Fistulotomy. Journal of Surgery. Special Issue: Surgical Infections and Sepsis. Vol. 4, No. 3-1, 2016, pp. 10-13. doi: 10.11648/j.js.s.2016040301.12

Received: January 28, 2016; Accepted: January 29, 2016; Published: March 23, 2016

\begin{abstract}
Introduction: Perianal abscess is one of the most common general surgical emergencies encountered in clinical practice and the initial treatment is simple incision and drainage, other surgical procedures as fistulotomy may be required as a definitive measure for treating fistula because about $40 \%$ of patients present with a fistula after simple incision and drainage of their perianal abscesses. The aim of this study was to detect the outcome of simple drainage versus drainage and fistulotomy for perianal abscess as regard to abscess recurrence, fistula formation and time off from work. Patients and Methods: A total number of 200 patients of both sexes; 100 for each group, their ages ranged between 21- 65 years were enrolled to this parallel prospective randomized clinical trial where patients were divided randomly into two main groups; A and B. Group A patients $[\mathrm{N}=100]$ were subjected to simple incision \& drainage and those of group B [N =100] were subjected to drainage \& fistulectomy for acute perianal abscess. End Points: The primary end points were abscess recurrence, fistula formation and incontinence. The secondary end points were time off from work, wound discharge, wound healing and patients' satisfaction. Results: Patient's satisfaction of the treatment maneuver in relation to abscess recurrence and fistula occurrence was $80 \%$ and $95 \%$ of group A and B respectively. Conclusion: The present study showed that treatment of perianal abscess through the combined maneuver of incision - drainage with fistulotomy at the same time significantly reduced the likelihood of persistent abscess, recurrence and need for repeat surgery. Patient's satisfaction after treatment with this combined method showed a significant value than incision - drainage only as regard disease recurrence, time of wound discharge and the incidence of fistula formation.
\end{abstract}

Keywords: Perianal Abscess, Simple Drainage, Fistulotomy

\section{Introduction}

Perianal abscess is one of the most common general surgical emergencies encountered in clinical practice and its surgical management is one of the most common surgical emergency procedures performed by the surgical team [1]. Perianal abscesses arise from anal glands which have a predisposition to get obstructed and suppurated leading to abscess formation. Perianal abscesses and anal fistula are often found together [2]. While the initial treatment of perianal abscess is simple incision and drainage, other surgical procedures as fistulotomy may be required as a definitive measure for treating fistula because about $40 \%$ of patients present with a fistula after simple incision and drainage of their perianal abscesses [1, 3]. Surgical intervention is recommended in case of spontaneous perforation since insufficient drainage may cause abscess recurrence or fistula formation. Conservative treatment options, particularly antibiotic treatment, are unlikely successful and are not considered appropriate [4]. After simple incision drainage of perianal abscess, the incidence of fistula occurrence is reported as $16 \%$ and abscess recurrence rate as $13 \%[3,5,6]$. The aim of this study was to detect the outcome of simple drainage versus drainage and fistulotomy for perianal abscess as regard to abscess recurrence, fistula formation and time off from work.

\section{Patients and Methods}

\subsection{Patients}

A total number of 200 patients of both sexes; 100 for each 
group, their ages ranged between 21- 65 years were enrolled to this parallel prospective randomized clinical trial where patients were divided randomly into two main groups; A and B. Group A patients $[\mathrm{N}=100]$ were subjected to simple incision \& drainage and those of group $\mathrm{B}[\mathrm{N}=100]$ were subjected to drainage \& fistulectomy for acute perianal abscess. The study started from January 2005 to December 2009 and included all patients having first attack of perianal abscess. Patients with recurrent abscesses or presence of fistula at the time of presentation were excluded. Written consents were obtained from all patients before the study. The steps of both operative interferences were explained to all patients. The local ethics committee had approved all operative procedures. Ethical approval for this study was granted by the ethical review committee under supervision of the general director of Port-Fouad general hospital, PortFouad, Port-Said, Egypt.

\subsection{Randomization}

Randomization was performed prior to study commencement as follows: Opaque envelopes were numbered sequentially from 1 to 200 . A computer-generated table of random numbers was used for group assignment; if the last digit of the random number was from 0 to 4 , assignment was to Group A (simple incision \& drainage), and if the last digit was from 5 to 9 , assignment was to Group B (drainage \& fistulectomy). The assignments were then placed into the opaque envelopes and the envelopes sealed. As eligible participants were entered into the trial, these envelopes were opened in sequential order to give each patient his or her random group assignment. The envelopes were opened by the operating surgeon after patient consent and just prior to the surgery.

\subsection{Operative Techniques}

Operations were performed in Port-Fouad general hospital, Port-Fouad, Port-Said, Egypt and in the university hospital, department of surgery, Faculty of medicine, Suez Canal University, Egypt. Really our patients were oriented to the type of operation and the other observers also were aware to operative techniques of the study groups. All the operative maneuvers were performed under general anaesthesia with patients in the lithotomy position. Patients were discharged on the first postoperative day and were advised regarding oral medication, maintenance of local hygiene, sitz bath after defecation, dressings, and regular follow-up.

1. In the simple incision \& drainage patients, per rectal examination was performed to detect the while size of the abscess. Cruciate incision was made to allow proper abscess drainage with examination of the abscess cavity by the opposite index finger. Lastly secured hemostasis was achieved by proper packing.

2. In the drainage \& fistulotomy patients, proper abscess drainage was done as before and the internal opening was searched using the anal probe. Then fistulotomy was done. Hemostasis was achieved.

\subsection{End Points}

The primary end points of the study were abscess recurrence, fistula formation and incontinence. Abscess recurrence and fistula formation were diagnosed on the clinical background according the decision of two examiners. Incontinence was assessed by using the Fecal Incontinence Severity Index (FISI), that allow patients to record the frequency of accidental leakage with gas, mucus, liquid, and/or solid stool:

1) No accidental leakage from anus (no fecal/flatal incontinence [no FI/FL]),

2) Leakage of gas only (isolated flatal incontinence only [isolated FL]), or

3) Accidental leakage of mucus, liquid or solid stool with or without leakage of gas (fecal incontinence [FI] with or without flatal incontinence) [7].

The secondary end points were time off from work, wound discharge, wound healing and patients' satisfaction. Time off from work was defined as the number of days between the day of surgery and the first day a patient returned to work [8]. Postoperative wound discharge was defined as a non-infected sero-sanguinous secretion coming from the open wound while complete healing of the postoperative wound was defined as full epithelialization of the wound [9]. and patients' satisfaction was measured according to abscess recurrence, fistula formation and occurrence of incontinence.

\subsection{Statistical Analysis}

The statistical tests were run on a compatible personal computer using the Statistical Package for Social Scientists (SPSS) for windows 15. Chi-square distribution was used for studying the frequencies of recurrence, pain, hospital stay and postoperative complications. The values were expressed as means \pm standard errors of deviation. The mean values of the groups were compared by one-way analysis of variance (ANOVA) and paired comparisons of the groups were done using the paired student $t$ test. $\mathrm{P}<0.05$ was considered significant.

\section{Results}

Concerning the demographic data as shown in table 1, there was no statistical significant difference between the two groups regarding age, sex, body mass index (BMI) and diabetes. In our series, $79 \%$ of our patients were gentlemen, $38 \%$ were $\geq 50$ years old and $36.5 \%$ were diabetics. There was neither operative nor 30 days postoperative mortality.

Table 1. Showed the demographic data of both groups.

\begin{tabular}{llllllllll}
\hline Group & $\begin{array}{l}\text { Age } \\
\text { (years) }\end{array}$ & Sex & & \multicolumn{2}{c}{ BMI $\left(\mathbf{k g} / \mathbf{m}^{2}\right)$} & \multicolumn{3}{c}{ Diabetes } \\
\cline { 2 - 10 } & $\mathbf{5 5 0}$ & $\mathbf{2 5 0}$ & Male & Female & $<\mathbf{2 5}$ & $>\mathbf{2 5 - 3 0}$ & $>\mathbf{3 0}$ & yes & no \\
\hline A & 60 & 40 & 80 & 20 & 20 & 65 & 15 & 38 & 62 \\
B & 64 & 36 & 78 & 22 & 19 & 64 & 17 & 35 & 65 \\
\hline
\end{tabular}

The operating time for the procedure was calculated from the start of abscess drainage to the beginning of dressing of 
the postoperative wound. The mean operative time in patients of group A was $23 \pm 5.21$ minutes and that for patients of group B was $25 \pm 4.68$ minutes with statistically insignificant distribution $\{P \geq 0.0996\}$. Abscess recurrence occurred in 11 patients $(11 \%)$ and in only 3 patients $(3 \%)$ in group $\mathrm{A}$ and $\mathrm{B}$ respectively while in fistula occurrence, $9 \%$ and $2 \%$ in both groups respectively were observed with statistically insignificant distribution $\{P \geq 0.05\}$. Patient's satisfaction of the treatment maneuver in relation to abscess recurrence and fistula occurrence was $80 \%$ and $95 \%$ of group A and B respectively.

Regarding the occurrence of fecal incontinence, no permanent cases were reported in our series but temporary incontinence was observed only in 2 patients in fistulotomy group B. According to Fecal Incontinence Severity Index, none of our patients showed fecal incontinence and only the two of group B were temporarily incontinent to gases that subsided gradually and these two patients were women above 50 years. We detected that $100 \%$ and $98 \%$ of group A and B respectively were satisfied of the treatment maneuver.

The time taken for wound to heal completely according to the proposed protocol in our methodology was 20-36 days with mean value $28 \pm 4.97$ days and $21-45$ days with mean value $31.8 \pm 8$ in group $A$ and $B$ respectively with statistically significant distribution $\{P \leq 0.0216\}$. As regard the time taken for complete wound healing, we detected that $20 / 100$ patients in group A and 5/100 patients in group B were unsatisfied of the treatment maneuver.

The overall patient satisfaction was calculated in our study as the sum of individual satisfaction for each parameter according the questionnaire prepared by the treating surgical team and signed by the patients themselves. Regarding abscess recurrence and fistula occurrence, patient's satisfaction of the treatment maneuver was $80 \%$ and $95 \%$ of group $\mathrm{A}$ and $\mathrm{B}$ respectively. In case of anal incontinence, there were $100 \%$ and $98 \%$ of patients in group A and B seemed satisfied. For the time taken for wound discharge to cease and that taken for wound to heal completely, patient satisfaction was shown in table 2. Therefore, the overall patient satisfaction mean values were $86.6 \pm 11.54$ and $96 \pm 1.73$ for patients in group A and B respectively with extremely statistical significant distribution $\{\mathrm{P} \leq 0.0001\}$

Table 2. Showed patient's satisfaction of the treatment maneuvers.

\begin{tabular}{llll}
\hline Parameters & Group A & Group B & Significance \\
\hline Abscess \& fistula & 80 & 95 & \\
Incontinence & 100 & 98 & $\mathrm{P} \leq 0.0001$ \\
Wound discharge & 82 & 74 & $\mathrm{~T}=8.0041$ \\
Recurrence & 80 & 95 & $\mathrm{df}=198$ \\
Total: Mean \pm SD & $86.6 \pm 11.54$ & $96 \pm 1.73$ & \\
\hline
\end{tabular}

\section{Discussion}

In the present study, the male gender predominance (79\%) and those with age $\leq 50$ years $(38 \%)$ came in concordance with those reported in studies of same interest $[10,11]$ and other studies reported that perianal abscesses are seen two times more frequently in men than in women $[2,4,12]$. In agreement with our finding, it was stated that the peak incidence of perianal abscesses is in the third or fourth decade of life and it is two or three times more common in men than women with diabetes and increased BMI as the major traced risk factors for development of perianal abscesses [13, 14 ]. Our data reported that higher abscess recurrence and fistula formation after the treatment modalities using incision \& drainage of perianal abscess and this finding was in concordance with other published data that reported abscess recurrence rate of $29 \%$ incision/drainage group as compared with $5 \%$ of the fistulotomy group $[15,16]$. Other studies of same interest reported that acute abscess recurrences occur in $10 \%$ and development of chronic fistula-in-ano occurs in up to $50 \%$ of patients [17] while another stated that $31 \%$ of patients developed fistula-in-ano following incision and drainage [18]. The decision of whether or not to perform a fistulotomy during the original incision and drainage of perianal abscess has been debated in the literature [2, 19]. In a randomized clinical trial done by Oliver and colleagues compared simple drainage abscess drainage with and without fistula track treatment to evaluate the effectiveness and morbidity of both operations in the management of acute anal sepsis. They found that drainage of the abscess with fistulotomy can be safely performed in cases of subcutaneous, intersphincteric, or low transsphincteric fistula with a minimal recurrence rate as $5 \%$ compared with $29 \%$ recurrence rate in patients treated with drainage alone [16]. Incontinence rates following fistulotomy depends on both the amount of muscle divided at the time of operation as well as any preexisting previous sphincter damage causing scarring of the anal canal [2, 20, 21]. Incontinence rates have been reported in previous reports to range from $18 \%$ to $52 \%[2,22,23]$. Oliver and his colleagues found zero \% incontinence in drainage only and $6 \%$ in drainage with fistulotomy [16]. Regarding the time to complete healing, the mean time was 18 (range 10-53) days and 26 (range 18-40) days after drainage alone versus fistulotomy respectively $[19,24]$.

Patient satisfaction after surgery for anal diseases depends on factors like period of hospitalization, postoperative pain and bleeding, return to routine activity, wound care, wound healing time, interference with the anal continence and recurrence. The majority of patients subjected to surgery for anal problems attributed their dissatisfaction to recurrence and anal incontinence following surgery [25]. In our study, satisfaction was much more in patients treated with abscess drainage and fistulotomy than those treated as drainage only as a result of less recurrence, less wound discharge and lower incidence of fistula formation.

\section{Conclusion}

The present study showed that treatment of perianal abscess through the combined maneuver of incision drainage with fistulotomy at the same time significantly reduced the likelihood of persistent abscess, recurrence and need for repeat surgery. Patient's satisfaction after treatment 
with this combined method showed a significant value than incision - drainage only as regard disease recurrence, time of wound discharge and the incidence of fistula formation.

\section{References}

[1] Malik A, Hall D, Devaney R, Sylvester H, Yalamarthi S. The impact of specialist experience in the surgical management of perianal abscesses. Int J Surg. 2011; 9(6): 475-7.

[2] Sneider EB, Maykel JA. Anal abscess and fistula. Gastroenterol Clin North Am. 2013; 42(4): 773-84.

[3] Hamadani A, Haigh PI, Liu IL, Abbas MA. Who is at risk for developing chronic anal fistula or recurrent anal sepsis after initial perianal abscess? Dis Colon Rectum, 2009 (52): 217 221.

[4] Ommer A, Herold A, Berg E, Fürst A, Sailer M, Schiedeck T. German S3 guideline: anal abscess. Int J Colorectal Dis. 2012; 27: $831-837$.

[5] Lohsiriwat V, Yodying H, Lohsiriwat D. Incidence and factors influencing the development of fistula-in-ano after incision and drainage of perianal abscesses. J Med Assoc Thai 2011; 93: 61-65.

[6] Sözener U, Gedik E, Kessaf Aslar A, Ergun H, Halil Elhan A, Memikoğlu O, Bulent Erkek A, Ayhan Kuzu M.. Does adjuvant antibiotic treatment after drainage of anorectal abscess prevent development of anal fistulas? A randomized, placebo-controlled, double-blind, multicenter study. Dis Colon Rectum. 2011; 54: 923-929.

[7] Imhoff LR, Brown JS, Creasman JM, Subak LL, Van den Eeden SK, Thom DH, Varma MG, Huang AJ. Fecal incontinence decreases sexual quality of life, but does not prevent sexual activity in women. Dis Colon Rectum. 2012; 55(10): 1059-65.

[8] Saber A, Ellabban GM, Gad MA and Elsayem K. Open preperitoneal versus anterior approach for recurrent inguinal hernia: a randomized study. BMC Surgery 2012, 12:22 doi: $10.1186 / 1471-2482-12-22$.

[9] Jain BK, Vaibhaw K, Garg PK, Gupta S and Mohanty D. Comparison of a Fistulectomy and a Fistulotomy with Marsupialization in the Management of a Simple Anal Fistula: A Randomized, Controlled Pilot Trial. J Korean Soc Coloproctol. 2012; 28(2): 78-82.

[10] Czeiger D, Shaked G, Igov I, Pinsk I, Peiser J, Sebbag G. High occurrence of perianal abscess among Bedouin compared to Jews in the southern region of Israel. BMC Surg. 2013; 12; 13: 35. doi: 10.1186/1471-2482-13-35.

[11] De Oliveira PG; de Sousa JB; de Almeida RM; Wurmbauer IFS; dos Santos CAN and Filho JG. Anal fistula: results of surgical treatment in a consecutive series of patients. J. Coloproctol. (Rio J.), 2012; 32 (1): 60-64.
[12] Abcarian H. Anorectal infection: abscess-fistula. Clin Colon Rectal Surg. 2011, 24 (1): 14-21.

[13] Ulug M, Gedik E, Girgin S, Celen MK, Ayaz C. The evaluation of bacteriology in perianal abscesses of 81 adult patients. Braz J Infect Dis. 2010; 14(3): 225-9.

[14] Wei PL, Keller JJ, Kuo LJ, Lin HC. Increased risk of diabetes following perianal abscess: a population-based follow-up study. Int J Colorectal Dis. 2013; 28(2): 235-40.

[15] Rizzo JA, Naig AL, Johnson EK. Anorectal abscess and fistula-in-ano: evidence-based management. Surg Clin North Am. 2010; 90(1): 45-68.

[16] Oliver, F. J. Lacueva, F. P. Vicente, et al. Randomized clinical trial comparing simple drainage of anorectal abscess with and without fistula track treatment. Int J Colorectal Dis, 2003, 18; 107-110.

[17] Whiteford MH. Perianal Abscess/Fistula Disease. Clin Colon Rectal Surg. May 2007; 20(2): 102-109.

[18] Lohsiriwat V, Yodying H, Lohsiriwat D. Incidence and factors influencing the development of fistula-in-ano after incision and drainage of perianal abscesses. J Med Assoc Thai. 2010; 93(1): 61-5.

[19] Malik AI, Nelson RL, Tou S. Incision and drainage of perianal abscess with or without treatment of anal fistula. Cochrane Database Syst Rev. 2010, 7; (7): CD006827. doi: 10.1002/14651858.CD006827.

[20] Ege B, Leventoğlu S, Menteș BB, Yılmaz U and Öner AY. Hybrid seton for the treatment of high anal fistulas: results of 128 consecutive patients. Tech Coloproctol. 2014; 18(2): 187193.

[21] Bokhari S, Lindsey I. Incontinence following sphincter division for treatment of anal fistula. Colorectal Dis. 2010; 12: $35-39$.

[22] Sharma D, Pipariya PR, Gupta S, Gupta A and Chopra N. Fistulectomy or Fistulotomy: Better Approach in Fistula-InAno. Sch. J. App. Med. Sci., 2014; 2(1B): 202-204.

[23] Quah HM, Tang CL, Eu KW, et al. Meta-analysis of randomized clinical trials comparing drainage alone vs primary sphincter-cutting procedures for anorectal abscessfistula. Int J Colorectal Dis 2006; 21(6): 602-9.

[24] Inceoglu R and Gencosmanoglu R. Fistulotomy and drainage of deep postanal space abscess in the treatment of posterior horseshoe fistula. BMC Surgery 2003, 3:10 doi: 10.1186/1471-2482-3-10.

[25] Saber A. Patients Satisfaction and Outcome of Fistulotomy versus Fistulectomy for Low Anal Fistula. Journal of Surgery. Special Issue: Gastrointestinal Surgery: Recent Trends. 2016, 4(2-1): 15-19. 